\title{
Kenneth Ring's Swan Song
}

To the Editor:

This letter was motivated by, but is not about, Kenneth Ring's apparent swan song in a recent issue of this Journal, in which he 
wrote: "my work in near-death studies was now concluded... I am inclined to believe [this decision] had something to do with the depth of insight as well as the extended character of the [near-death] accounts I have quoted here" (Ring, 1991, p. 34). In that article, Ring provided moving accounts of four personal near-death experiences (NDEs), each magnificently told in the NDEr's own words.

That Ring has finally seen the light (hardly a pun in this business) is to be applauded. On the other hand it doesn't make sense that after ten years of research a near-death guru's decision to quit should come from something NDErs have been talking about all along; surely I missed something in his explanation? His decision to exit near-death research came at exactly the juncture at which a researcher might best be entering, which brings me to the point of this letter.

I believe the paramount goal of near-death research only begins, not ends, with intimately presented word-pictures of spiritual encounters. The publication of these encounters serves as prefatory grounding-an introduction, not a conclusion-for those who need to record next what they have or have not done with life in fulfillment of a pledge made on the higher plane, a pledge all NDErs contract for, whether or not consciously remembered.

My suggestion is for research into life after life-after-life on a grand scale quite beyond what has already been done in limited sample sizes. I'd like to see study of life after the NDE given time and energy expenditures equal to those previously accorded the spiritual encounter itself. Some who know say that one result might well be a clear understanding of why we have near-death visions.

Early on we would learn that "experiencer" is an inadequate and ambiguous descriptor. As an alternative, NDEr and author P. M. H. Atwater (1988) paved the way by explicitly covering the field with a better one-word descriptor: "survivor."

Of course, Buddha, Jesus, Martin Luther, Mahatma Gandhi, and others have survived a spiritual vision that was nothing if not a painful stumbling for survival in a world in which they found themselves to be "different." And every one knows what they did with their post-vision lives.

Near-death survivors, and many UFO abductees, are in the same boat in coming back to Earth never again to be the same. Yet despite the fact that the spiritual trauma inherited from a near-death vision inherently precludes business as usual, many NDErs seem to stagnate spiritually within the coverup of a variety of pretexts. Studied as a group, their post-NDE lives have much to offer the world. 
My qualifications for suggesting greatly expanded and entirely new researches into the NDE's impact come partly from my own life-not the pre-NDE life I surrendered but the new post-NDE life I entered, the one in which I chose to become a stumbling wanderer in order to fulfill the contract I had made but couldn't name until long after I first cut adrift. The other source of my qualifications for asking to be heard stems from chance encounters here and there with kindred spirits to near-death survivors, especially those pathetic souls who in allegiance to their former constraints try to force-fit what they have become into the previously familiar space they had once occupied.

All too often those encounters with kindred spirits were moments of bitter failure due to my lack of talents with which to be of convincing help. But maybe near-death researchers can help by broadcasting interesting reports of benefit to impacted survivors. To begin with, I'd like to see some explanation of why some of us left all we were or had in order to wander around unfathomably in a world now new to us. Of the ten to twenty million Americans estimated to be near-death survivors, is it possible I am the only crazy in town? If not, how many others might there be? What are our commonalities, before, during, and after the NDE? Questions about effects rather than causes will escalate when other NDErs are invited to contribute their ideas for research. Trust us to know intuitively what you need to explore.

Ultimately these proposed studies of near-death survivors' afterworld journeys will offer more enlightenment than would studies of neardeath survivors' otherworld journeys. I hope that IANDS will one day find itself generously offering the Journal or an alternate publication's pages to the full-bore accounts of NDEs' impact as written by those who were abruptly hurled into their new lives. It is inevitable that if done in depth via a thousand "amazing grace" narratives complete with post-NDE accounts, major surprises are in store.

A thousand narratives? More likely ten thousand times a thousand potential stories from souls waiting in line to tell their all! But not via self-defeating questionnaires; after all, what could be more individually emotional than death, except a return from death? How then can we compress our experiences into sanitized form responses? True, data in prose form require much more effort to evaluate, but as some have belatedly discovered, that's the only way to get it all.

You have to wonder, though, if only four top-notch recitals prompted one researcher to jump bail, what might a few dozen or a hundred do to the others? 


\section{References}

Atwater, P. M. H. (1988). Coming back to life New York, NY: Dodd, Mead.

Ring, K. (1991). Amazing grace: The near-death experience as a compensatory gift. Journal of Near-Death Studies, 10, 11-39.

Vincent Luciani

218 West Revere Avenue

Northfield, NJ 08225

[Editor's Note: The Journal has always been willing to publish NDErs' accounts of their "afterworld" journeys, such as Sally Leighton's "God and the God-Image: An Extended Reflection" (Volume 9, Number 4), John Wren-Lewis's "The Darkness of God: An Account of Lasting Mystical Consciousness Resulting from an NDE" (Volume 5, Number 2), and Patrick Gallagher's "Over Easy: A Cultural Anthropologist's Near-Death Experience" (Volume 2, Number 2). We welcome further accounts from NDErs written in an appropriate style, and second Vincent Luciani's call for researchers to take cues from these accounts. In addition, Vital Signs, IANDS's quarterly newsletter, regularly publishes NDErs' accounts written in a shorter and less academic format.] 